\title{
GMR
}

\section{Mitochondrial DNA dynamics during in vitro culture and pluripotency induction of a bovine Rho0 cell line}

\author{
L.V.F. Pessôa ${ }^{1}$, F.F. Bressan ${ }^{1,2}$, M.R. Chiaratti ${ }^{1,3}$, P.R.L. Pires ${ }^{1}$, F. Perecin ${ }^{1,2}$, \\ L.C. Smith ${ }^{1,4}$ and F.V. Meirelles ${ }^{1,2}$ \\ 1Departamento de Cirurgia, Faculdade de Medicina Veterinária e Zootecnia, \\ Universidade de São Paulo, São Paulo, SP, Brasil \\ ${ }^{2}$ Departamento de Medicina Veterinária, Faculdade de Zootecnia e Engenharia de \\ Alimentos, Universidade de São Paulo, Pirassununga, SP, Brasil \\ ${ }^{3}$ Departamento de Genética e Evolução, Centro de Ciências Biológicas e da Saúde, \\ Universidade Federal de São Carlos, São Carlos, SP, Brasil \\ ${ }^{4}$ Animal and Reproduction Research Center, Université de Montréal, Montréal, Canada \\ Corresponding author: L.V.F. Pessôa \\ E-mail: laisvpessoa@usp.br
}

Genet. Mol. Res. 14 (4): 14093-14104 (2015)

Received May 18, 2015

Accepted October 14, 2015

Published October 29, 2015

DOI http://dx.doi.org/10.4238/2015.October.29.29

ABSTRACT. Large number of cellular changes and diseases are related to mutations in the mitochondrial DNA copy number. Cell culture in the presence of ethidium bromide is a known way of depleting mitochondrial DNA and is a useful model for studying such conditions. Interestingly, the morphology of these depleted cells resembles that of pluripotent cells, as they present larger and fragmented mitochondria with poorly developed cristae. Herein, we aimed to study the mechanisms responsible for the control of mitochondrial DNA replication during mitochondrial DNA depletion mediated by ethidium bromide and during the in vitro induction of cellular pluripotency with exogenous transcription factor expression in a bovine model. This article reports the generation of a bovine Rho0 mesenchymal cell line and describes the analysis of mitochondrial DNA 
copy number in a time-dependent manner. The expression of apoptosis and mitochondrial-related genes in the cells during mitochondrial DNA repletion were also analyzed. The dynamics of mitochondrial DNA during both the depletion process and in vitro reprogramming are discussed. It was possible to obtain bovine mesenchymal cells almost completely depleted of their mitochondrial DNA content (over 90\%). However, the production of induced pluripotent stem cells from the transduction of both control and Rho0 bovine mesenchymal cells with human reprograming factors was not successful.

Key words: mtDNA; Depletion; Pluripotency; Induced cells; Cattle

\section{INTRODUCTION}

Mitochondria are maternally inherited organelles that play an essential role in cellular energetic metabolism, homeostasis, and death by generating most of the ATP necessary for energy-dependent biological processes through the oxidative phosphorylation (OXPHOS) pathway (Anderson et al., 1981). These organelles exhibit their own genetic material, termed mitochondrial DNA (mtDNA), which is responsible for synthesizing 13 essential polypeptides for mitochondrial activity (Shadel and Clayton, 1997). Each cell harbors between 1 and 10 mitochondria, with multiple copies of mtDNA, which are related to its capacity for energy production (Reynier et al., 2001). Recently, mitochondria have been described to vary in number (St John et al., 2005) and morphology according to the cellular differentiation state; in pluripotent cells, mitochondria have swollen and poorly developed cristae (Sathananthan et al., 2002; Facucho-Oliveira and St John, 2009; Ramalho-Santos et al., 2009) that undergo changes during cellular differentiation (Facucho-Oliveira et al., 2007).

Embryonic stem (ES) cells have few copies of oocyte-derived mtDNA (Shoubridge and Wai, 2007) because mtDNA replication does not occur during the early stages of development (Thundathil et al., 2005), thus decreasing the number at each cell division (Shoubridge and Wai, 2007). This mechanism might be an attempt to protect mitochondria and mtDNA from possible damage caused by reactive oxygen species (ROS) because ES cells do not seem to rely on OXPHOS for energy supply (Armstrong et al., 2010). mtDNA replication proceeds and increases with cell differentiation. Therefore, mitochondria become mature and capable of oxidative metabolism only during and after the blastocyst stage (Facucho-Oliveira et al., 2007; reviewed by St John et al., 2010).

A series of cellular changes and diseases are closely related to mutations in the number of mtDNA copies (King and Attardi, 1996; Scarpulla, 2008). One way to mimic these changes in the number of mtDNA copies, in vitro, is mitochondrial depletion by exposing the cultured cells to ethidium bromide $(\mathrm{EtBr})$, which inhibits mtDNA replication and, hence, decreases the number of mtDNA copies (Nass, 1970). Interestingly, the morphology of these mitochondria-depleted cells greatly resembles that of pluripotent cells (Sathananthan et al., 2002; Facucho-Oliveira and St John, 2009; Ramalho-Santos et al., 2009) because they present mitochondria that are larger than those of normal cells but are fragmented and have spaced out and poorly developed cristae (Nass, 1970; Marusich et al., 1997).

Herein, we aimed to study the mechanisms responsible for the control of mtDNA replication during mtDNA depletion mediated by $\mathrm{EtBr}$ in mesenchymal cells. The effect of $\mathrm{EtBr}$ during the induction of pluripotency in bovine cells, through the expression of exogenous transcription factors, was also studied. This article describes the development of a bovine Rho0 mesenchymal cell line and the depletion of the mtDNA during the introduction of reprogramming factors. 


\section{MATERIAL AND METHODS}

\section{Cell line establishment}

A mesenchymal stem cell line was derived from a fragment of adipose tissue from the base of the tail of a female Nellore (Bos indicus). Briefly, the tissue was reduced to small pieces and incubated in $0.1 \%$ collagenase (Sigma, St. Louis, MO, USA) for $3 \mathrm{~h}$ at $38.5^{\circ} \mathrm{C}$. After inactivation of the collagenase and centrifugation at $300 \mathrm{~g}$ for $5 \mathrm{~min}$, the cell pellet was suspended in Iscove's modified Dulbecco's media (IMDM, Life Technologies, Grand Island, NY, USA), supplemented with $10 \%$ fetal calf serum (FCS, Gibco, Grand Island, NY, USA), $100 \mathrm{mg} / \mathrm{mL}$ pyruvate and $1 \%$ antibiotic, and cultured on $35 \mathrm{~mm}$ diameter dishes at $38.5^{\circ} \mathrm{C}$ in an atmosphere of $5 \% \mathrm{CO}_{2}$ and maximum humidity. Tests for the presence of mycoplasmal contamination were not performed. During the experiments, all the cells were cultured on $100 \mathrm{~mm}$ diameter dishes in IMDM supplemented with 10\% FCS and 1\% penicillin/streptomycin (Gibco, Grand Island, NY, USA). The cells were characterized as mesenchymal by immunostaining for surface antigens and by their in vitro differentiation into adipocytes, chondrocytes and osteocytes, following the procedures previously described by our group (Sampaio et al., 2015).

\section{mtDNA dynamics after EtBr treatment}

Bovine mesenchymal stem cells were divided into two groups: a control group consisting of untreated cells and an EtBr group consisting of cells treated with ethidium bromide (EtBr, Sigma, St. Louis, MO, USA). These cells were cultured in vitro for 13 days under the conditions mentioned above. However, the medium was supplemented with $\mathrm{EtBr}(100 \mathrm{ng} / \mathrm{mL}$; EtBr group) and uridine (50 $\mu \mathrm{g} / \mathrm{mL}$; both groups), as suggested by King and Attardi (1996).

In this experiment, $4.0 \times 10^{5}$ cells were seeded in 100-mm-diameter dishes. The cells were replated every 3 days, and samples were collected and analyzed at each passage. After 13 days of treatment, the cells were plated on $35 \mathrm{~mm}$ culture dishes and treated again for another $24 \mathrm{~h}$ with EtBr. On the $14^{\text {th }}$ day, the culture medium containing EtBr was removed from part of the cells for 12 days. From this point on, cells were categorized into three groups: $\mathrm{EtBr}-\mathrm{C}$ : untreated group; $\mathrm{EtBr}-\mathrm{T}$ : cells that were kept in culture with $\mathrm{EtBr}$, and $\mathrm{EtBr}-\mathrm{R}$ group: cells in the culture from which $\mathrm{EtBr}$ was removed. During this period, samples were collected at $0,3,6,12$, and $24 \mathrm{~h}$ and 2, 3, 7, and 12 days to evaluate the mtDNA copy number. Furthermore, the effect of EtBr on cell morphology was evaluated by optical microscopy at each passage.

\section{Determination of the mtDNA copy number}

The mtDNA copy number was estimated at each cell passage, as previously described (Nicklas et al., 2004). Briefly, the samples were subjected to total DNA extraction based on the $\mathrm{NaCl}$ method (adapted from Miller et al., 1988) The extracted DNA was quantified by spectrophotometry (NanoDrop 2000, Thermo Scientific, Waltham, MA, USA) and frozen at $-80^{\circ} \mathrm{C}$. mtDNA quantification was then performed on a real-time PCR thermocycler (Applied Biosystems, 7500 Fast Real Time PCR System, Foster City, CA, USA) using TaqMan ${ }^{\circledR}$ system Assays (Applied Biosystems, Foster City, CA, USA) following the manufacturer instructions. The samples were analyzed in duplicate using the endogenous beta actin gene (ACTB) as a control and primers listed in Table 1. 
Table 1. Primers used for relative quantification of the target gene (mtDNA) and the endogenous control (ACTB).

\begin{tabular}{lllc}
\hline Target Gene (GenBank accession No.) & Primer & Sequence (5'-3') & Product (bp) \\
\hline ACTB & ACTB-f & GGCACCCAGCACAATGAAGA \\
(NM_173979.3) & ACTB-r & GCCAATCCACACGGAGTACTT \\
& ACTB-FAM & FAM-TCAAGATCATCGCGCCCCC-NFQ \\
Mt-RNR 2 & bMT3010-f & GCCCTAGAACAGGGCTTAGT & 67 \\
(AY526085 / AY126697) & bMT3096-r & GGAGAGGATTTGAATCTCTGG & 87 \\
& bMT3030-FAM & FAM-AAGGTGGCAGAGCCCGGTAATTGC-BHQ \\
\hline
\end{tabular}

\section{Semi-quantitative gene expression analysis of depleted cells}

Cell samples were pelleted by centrifugation and stored at $-80^{\circ} \mathrm{C}$. Total RNA was extracted from the samples using TRIzol $^{\circledR}$ reagent (Life Technologies, Grand Island, NY, USA) according to manufacturer recommendations. The extracted RNA was subjected to reverse transcription using the High Capacity RNA-to-cDNA Kit (Applied Biosystems, Foster City, CA, USA) following the manufacturer instructions. Quantification of gene expression was performed on the real-time PCR thermocycler. The relative quantification of the target genes (BAX,BCL-2, and TFAM; Table 2) and the endogenous control $(A C T B)$ was performed using the SYBR ${ }^{\circledR}$ Green PCR system (Applied Biosystems, Foster City, CA, USA) and $0.2 \mathrm{mM}$ of each oligonucleotide primer in a $20-\mu \mathrm{L}$ reaction, using specific primers (Table 2). The reaction was initiated by incubation at $50^{\circ} \mathrm{C}$ for 2 min, followed by denaturation at $95^{\circ} \mathrm{C}$ for $10 \mathrm{~min}$, and 45 cycles of $95^{\circ} \mathrm{C}$ for $15 \mathrm{~s}$ and $60^{\circ} \mathrm{C}$ for $1 \mathrm{~min}$. Each sample was evaluated in duplicate for all genes in all reactions.

\begin{tabular}{|c|c|c|c|}
\hline Target Assay (GenBank accession No.) & Primer & Sequence $\left(5^{\prime}-3^{\prime}\right)$ & Product (bp) \\
\hline ACTB & ACTB-f & GGCACCCAGCACAATGAAGA & 67 \\
\hline (NM_173979.3) & ACTB-r & GCCAATCCACACGGAGTACTT & \\
\hline BCL-2 & $B C L-2-f$ & GCACCTGCACACCTGGAT & 72 \\
\hline (XM_586976.4) & BCL-2-r & CGCATGCTAGGGCCATACAG & \\
\hline $\mathrm{BAX}^{-}$ & $B A X-f$ & GTTGTCGCCCTTTTCTACTTTGC & 89 \\
\hline (XM_586976.4) & BAX-r & CAGCCCATGATGGTCCTGATC & \\
\hline TFAM & TFAM-f & TTGGAAAAAGAAATCATGCAGAAACGT & 96 \\
\hline (NM_001034016.2) & TFAM-r & TGAGCGAGGTCTTTTTCGGTTTT & \\
\hline
\end{tabular}

\section{PCR data analysis}

To analyze the gene expression, we generated a standard curve using five serial dilutions $(1: 1)$ of the control sample. From the slope of the curve (Slope) and the "Ct" values, we calculated the amplification efficiency $\left\{E=10^{[(-1 / \text { SLOPE)-1] }}\right\}$ individually for each gene studied, as described by Livak and Schmittgen (2001). Mathematical procedures were then used to determine the expression level of the target genes relative to the endogenous gene.

\section{Pluripotency induction}

A lentiviral polycistronic excisable vector STEMCCA (Stem cell cassette; Sommer et al., 2009) containing human pluripotency factors (OCT4, SOX2, c-MYC, and KLF4) was produced by 
the lipofection of 293FT cells (Invitrogen, Carlsbad, CA, USA) with the lipofectamine 2000 reagent (Invitrogen, Carlsbad, CA, USA) and introduced to the bovine mesenchymal cells' genomes (both control and $\mathrm{EtBr}$ groups). Bovine mesenchymal cells were plated the day before at a concentration of $10^{5}$ cells per well in 6 -well plates with $50 \mu \mathrm{L}$ the viral concentrate and $8 \mu \mathrm{g} / \mathrm{mL}$ polybrene (hexadimethrine bromide, Sigma, St. Louis, MO, USA) in the medium, which was refreshed after every 12-16 $\mathrm{h}$ incubation. At 5- or 6-days-post-transduction, the cells were transferred to MEFs (murine embryonic fibroblasts) for a minimum of 14 days. Cells from the $\mathrm{EtBr}$ group had $\mathrm{EtBr}$ and uridine added to the medium.

The cell cultures were maintained in vitro for a minimum of 30 days and were collected at the specified time points for mtDNA analysis.

\section{Statistical analysis}

All statistical analyses were performed using SAS System (V9.2; SAS Institute, Inc., Cary, NC). Data were analyzed using analysis of variance (ANOVA) followed by the Student $t$-test, if necessary.

\section{RESULTS}

\section{Cell culture behavior and mtDNA copy number during the depletion and repletion processes}

In an attempt to obtain Rho0 cells, we exposed bovine mesenchymal cells to EtBr. After 13 days of treatment with $\mathrm{EtBr}$, the mtDNA quantification results showed a depletion by approximately $90 \%$ of the original mtDNA content compared with the control group $(P=0.0459)$. Analysis at different time points during the EtBr treatment (D4, D7, D10, and D13); on day 4 itself, the content of mtDNA had dropped to less than $10 \%$ of its original amount (Figure 1).

After 13 days of depletion, EtBr was removed from the culture medium, and the cells were cultured for an additional 2 days during which samples were collected. Although a recovery of the mtDNA copy number was expected, the number of copies remained similar to that of cells kept in culture with $\mathrm{EtBr}$ (Figure 2). There was a significant difference in the number of copies $(P<0.05)$ between the untreated group $(\mathrm{EtBr}-\mathrm{C})$ and the other groups. However, there were no differences $(\mathrm{P}<$ 0.05 ) between the EtBr-T and EtBr-R groups. Thus, the cells were then kept in culture without $\mathrm{EtBr}$ for an additional 10 days, but the repletion of the mtDNA copy number could not be detected (Figure 2).

\section{Depletion}

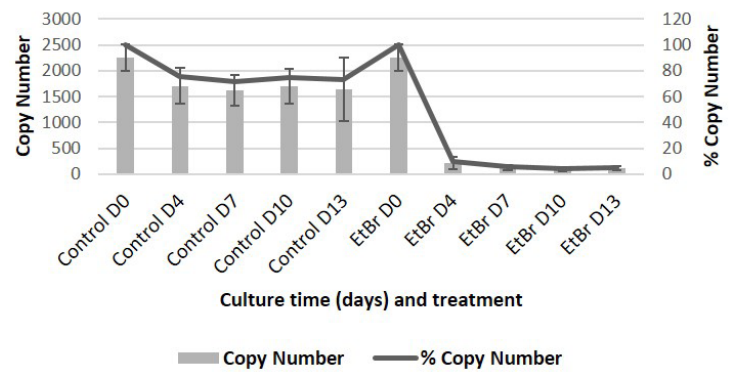

Figure 1. Depletion of mtDNA copies. Depletion of the mtDNA copy number of bovine adipose tissue-derived mesenchymal cells after 13 days of culture in the presence of EtBr. 


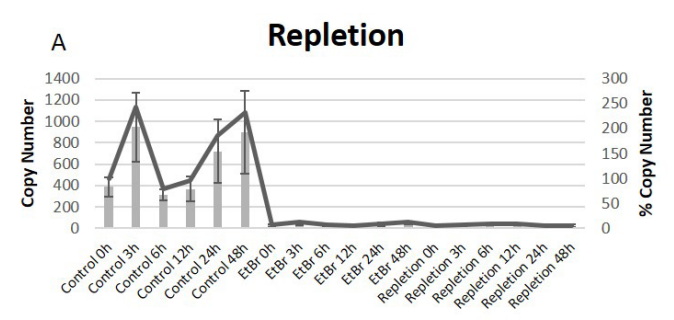

Culture time (hours) and treatment
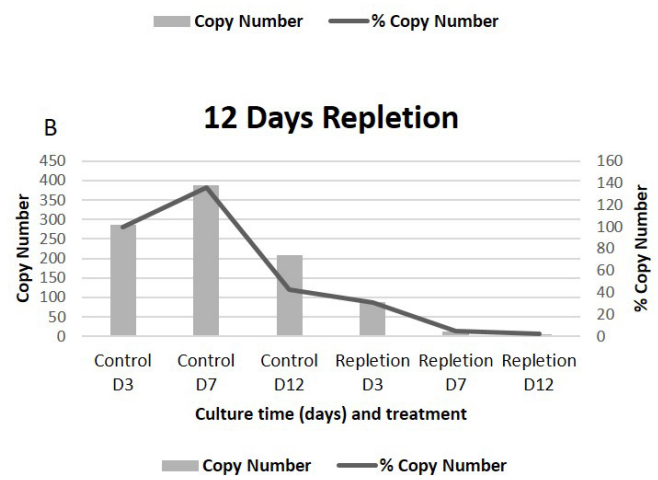

Figure 2. Recovery of mtDNA copy number. No sign of mtDNA copy number repletion was observed in bovine mesenchymal cells after either $48 \mathrm{~h}$ (A) or 12 days of culture (B) in the absence of EtBr following 13 days of depletion.

\section{Pluripotency induction}

Pluripotency factors were introduced to bovine mesenchymal cells from the control and $\mathrm{EtBr}$ groups using a STEMCCA lentivirus vector. After day 20, the transfected control cells presented a few structures that resembled induced pluripotent stem (iPS) cell colonies (Figure 3), but these formations were not maintained and the cells died shortly after. The depleted cells did not result in colony formation or other reprogramming characteristics, such as a round shape, large nuclei, or a small amount of cytoplasm. Despite the distinct decrease observed in the mtDNA copy number of the control cells after transduction ( $887.71 \pm 127.27$ and $503.47 \pm 170.33$ copies per cell, respectively, for the non-transduced control and transduced control cells), which suggests an effect of cellular reprogramming on the mtDNA levels, there was no significant difference among the cells from the control group. However, both cells treated with EtBr did differ from the cells of the control group $(P<0.05)$ after the introduction of the pluripotency factors (Figure 4$)$.

\section{Gene expression}

Considering the mitochondrial changes resulting from the depletion process and the role of mitochondria in apoptosis (Champelovier et al., 2013), the cells in this experiment were examined for the ratio of $B A X \mid B C L-2$ (Figure 5), which is decisive for cell fate (Nagata, 1997), and the expression of TFAM (Figure 6), a gene that represents the number of mtDNA copies in a cell (Schauen et al., 2006).

Regarding the depletion experiment, despite the decrease in mtDNA copy number, no differences in the expression levels of the target genes were observed. The values found for TFAM expression for treated and untreated cells were $1.12 \pm 0.21$ and $0.80 \pm 0.13$, respectively. However, 
an increase in the $B A X \mid B C L-2$ ratio was found in cells containing less mtDNA ( $1.06 \pm 0.34$ and 0.79 \pm 0.29 , respectively, for depleted and untreated cells).

In the repletion experiment, the $B A X \mid B C L-2$ ratio increased in the cells from both the EtBr-T and EtBr-R groups compared with the cells from the control group $(1.01 \pm 0.33,1.76 \pm$ 0.44 , and $1.66 \pm 0.43$, respectively, for untreated cells, depleted cells, and depleted cells after the removal of $\mathrm{EtBr}$ ). Again, however, no difference among the groups was found regarding the expression of TFAM $(0.56 \pm 0.15,0.28 \pm 0.11$, and $0.53 \pm 0.13$, respectively, for depleted cells, depleted cells after the removal of $\mathrm{EtBr}$, and control cells).

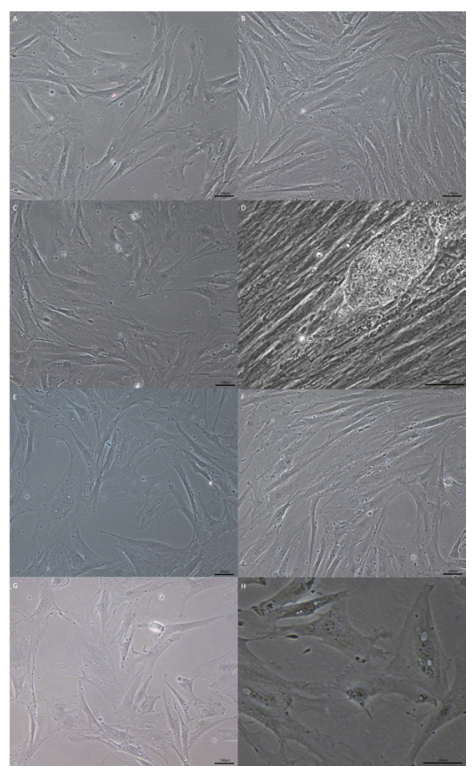

Figure 3. Depleted and control bovine mesenchymal stem cell expression during pluripotency induction. Micrographs of the studied cells during transduction. (A), (B) control cells not transfected with pluripotency factors at days 1 and 20 , respectively. (C), (D) Control cells transfected with pluripotency factors at days 1 and 20, respectively. (D) A structure resembling an iPS colony. However, this structure was not maintained and the cells died shortly after. (E), (F) Depleted cells not transfected with pluripotency factors at days 1 and 20, respectively. $(G),(H)$ Depleted cells transfected with pluripotency factors at days 1 and 20, respectively.

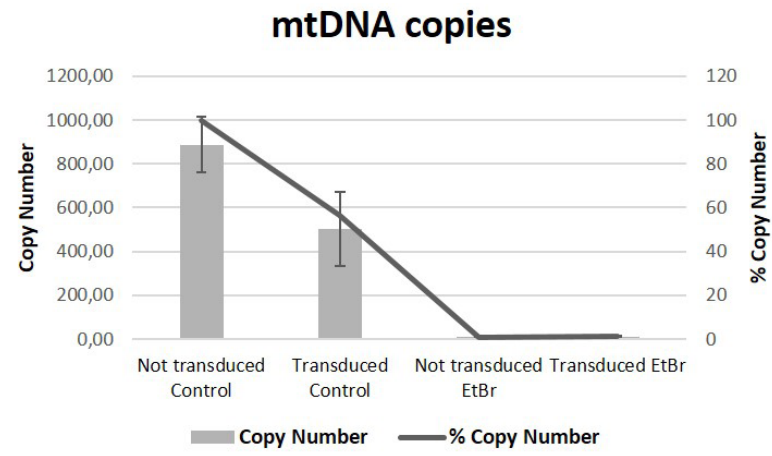

Figure 4. mtDNA copy number during pluripotency induction. mtDNA copy number and behavior of cells previously treated with $\mathrm{EtBr}$ for 13 days (group $\mathrm{EtBr}$ ) and control bovine mesenchymal cells during pluripotency induction. 
Regarding the pluripotency induction experiment, there was no difference between the groups for all the target genes studied. The values found for TFAM expression were $0.69 \pm 0.12$, $1.00 \pm 0.13,0.52 \pm 0.14$, and $1.16 \pm 0.12$, respectively, for untreated cells, untreated cells transfected with pluripotency factors, depleted cells, and depleted cells transfected with pluripotency factors. However, the values found for the $B A X \mid B C L-2$ ratio were $1.15 \pm 0.35,1.51 \pm 0.41,1.55 \pm 0.41$, and $1.52 \pm 0.41$, respectively, for untreated cells, untreated cells transfected with pluripotency factors, depleted cells, and depleted cells transfected with pluripotency factors.

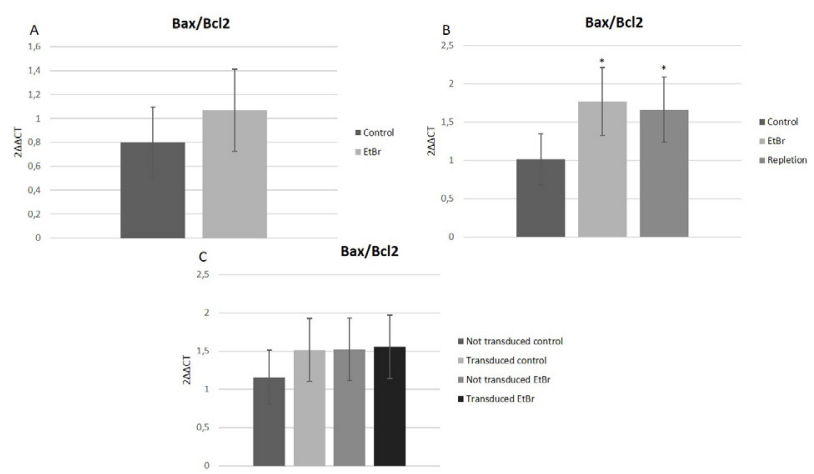

Figure 5. BAX/BCL-2 expression during mtDNA depletion. In (A) (depletion condition), when the cells were treated with $\mathrm{EtBr}$ for 48 hours no increase on BAX/BCL-2 ratio was observed, probably due to the shorter treatment period. In (B), cells treated with $\mathrm{EtBr}$ for 13 days showed an increased BAX/BCL-2 ratio. This was expected because apoptosis is closely related to the loss of mitochondrial membrane potential, and it is in agreement with the decreased cell proliferation observed after EtBr treatment. This increase was not observed in (C) during Pluripotency induction.

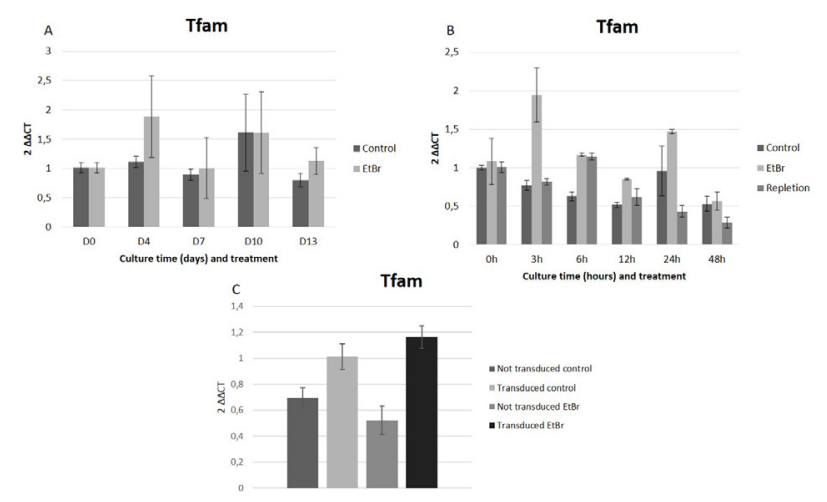

Figure 6. TFAM expression during mtDNA depletion. Despite the decreased mtDNA copy number, no differences in TFAM expression were observed between depleted and control cells in any of the experiments. (A) Depletion, (B) Repletion, (C) Pluripotency induction.

\section{DISCUSSION}

mtDNA depletion caused by treatment with $\mathrm{EtBr}$ has previously been described in the literature in rodent fibroblasts and liver cells (Nass, 1970) and in various human cells types (King and Attardi, 1996; Marusich et al., 1997; Seidel-Rogol and Shadel, 2002; Armand et al., 2004; 
Jeng et al., 2008; Magda et al., 2008; Mineri et al., 2009). Herein, we described the production of bovine mesenchymal Rho0 cells after 13 days in culture with EtBr. A decrease of approximately $90 \%$ in the mtDNA copy number was observed in these cells, and this decrease was maintained even after 12 days of culture in medium without EtBr. This result differs from that observed in HeLa cells depleted for 6 days, which showed signs of mtDNA repletion when cultured without EtBr for 12 days (Seidel-Rogol and Shadel, 2002). Depleted human 143B TK- cells also showed signs of mtDNA recovery when cultured for seven days without $\mathrm{EtBr}$ (Jeng et al., 2008). Depletion was expected once mtDNA replication had been inhibited by treatment with $\mathrm{EtBr}$, as this inhibition causes the initial number of mtDNA copies to be cut in half after each cellular division (Nass, 1970). The depleted cells also presented lower proliferation rates compared with control cells, similar to what has been observed for different depleted cell types, including MOLT-4 (Armand et al., 2004), A549 (Magda et al., 2008), and 143BTK- and A549 (Mineri et al., 2009). The bovine depleted cells produced in this experiment showed no morphological changes (Figure 7) compared with control cells, contrary to what Jeng et al. (2008) observed in depleted human 143B TK- cells.

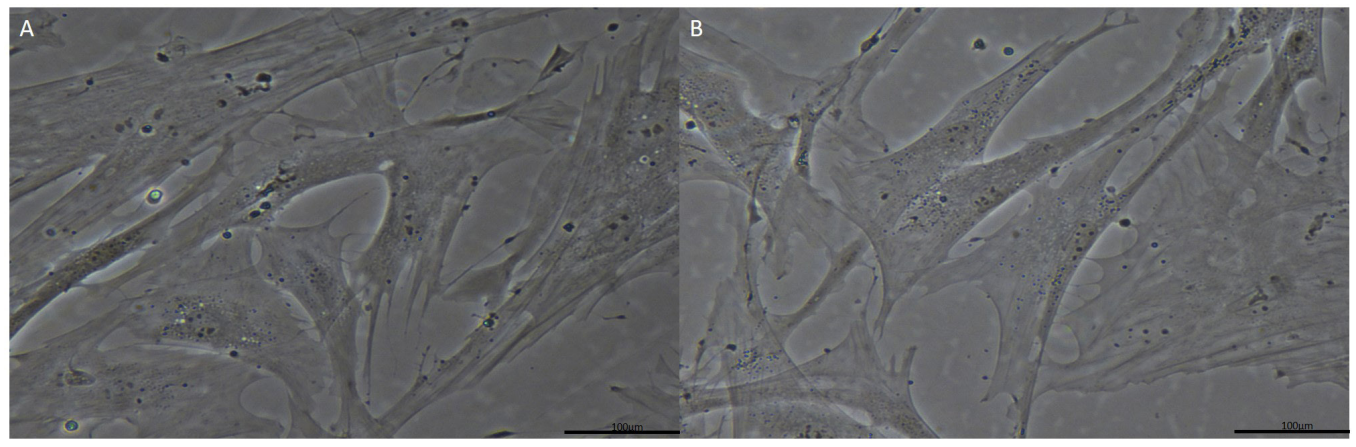

Figure 7. Morphological analysis of control and depleted cells. Regardless of what has been described in the literature (Jeng etal., 2008), when compared to control cells (A), bovine EtBr depleted cells (B) did not show morphological changes.

The regulation of the mtDNA copy number of a cell is essential during development, and this process is modified in the production of iPS cells (St John, 2014).

Furthermore, the mitochondria of pluripotent cells and cells depleted of mtDNA are similar in appearance (i.e., they are swollen and fragmented and have poorly developed cristae; Nass, 1970; Marusich et al., 1997; Armand et al., 2004). Thus, we hypothesized that the use of depleted cells for pluripotency induction would assist the reprogramming process because these cells would already present certain mitochondrial aspects of undifferentiated cells. However, when cells from the $\mathrm{EtBr}-\mathrm{T}$ and $\mathrm{EtBr}-\mathrm{C}$ groups were transduced with human exogenous transcription factors, we did not observe the formation of round shaped colonies or any other iPS cell characteristics (Figure 3).

Nevertheless, despite the absence of statistically significant differences when analyzing the mtDNA quantification data, we recognized that both groups of cells treated with $\mathrm{EtBr}$ (transduced or not transduced) and the transduced control group showed a decreased mtDNA copy number (Figure 4). This observation, due to the dedifferentiation factors, may be indicative of partial cellular reprogramming because a low mtDNA copy number is found in both embryonic stem cells and in iPS cells (Kelly et al., 2013).

Recent studies have highlighted the importance of metabolic reprogramming in the production of iPS cells. This reprogramming is associated with the transition of cell energy 
production from oxidative phosphorylation to glycolysis, which is highly important for cells with extensive proliferative potential: decreased mitochondrial oxidative stress (reviewed by Son et al., 2013) protects the cells from possible damage by ROS (Armstrong et al., 2010). iPS cells presented decreased levels of ATP compared with embryonic stem cells (ESCs), and while mtDNA depletion in pluripotent cells diminishes the mtDNA copy number, it does not decrease the amount of ATP, which suggests that oxidative phosphorylation is not the major source of energy for these cells (Kelly et al., 2013).

Despite evidence supporting a straightforward relationship between TFAM and the mtDNA copy number (reviewed by St John et al., 2010) and the fact that a low mtDNA copy number corresponds to non-existent levels of TFAM in bovine embryos up to the morula stage (St John, 2014), we did not find differences in TFAM expression for depleted and control cells in any of the experiments.

However, we did find an increased $B A X / B C L-2$ ratio in the depleted cells during both depletion and repletion experiments. This result was expected because apoptosis is a genetically controlled process that is closely related to the loss of mitochondrial membrane potential (Champelovier et al., 2013), and it is in agreement with the decreased cell proliferation that followed EtBr treatment. Moreover, there were no differences between the $\mathrm{EtBr}$ and control groups during pluripotent induction. This result may indicate that both transduction and treatment with $\mathrm{EtBr}$ lead to a reduction in the mtDNA copy number but are not sufficient to generate full reprogramming, either individually or in combination.

\section{CONCLUSION}

In this study, bovine mesenchymal cells depleted of more than $90 \%$ of their mtDNA content were obtained. To our knowledge, this is the first report of bovine Rho0 cells. The transduction of both the control and the Rho0 cells with human reprograming factors was not capable of producing bovine iPS cells. However, we were able to identify a change in the dynamics of mtDNA, which could be observed in the reduction of the mtDNA copy number in the transduced cells but was more intense when using depleted cells. Our results provide useful cues that may be important for future clinical applications. In summary, this work discusses the relationship between mitochondrial function and the cellular reprogramming process. However, further studies are needed to better understand these mechanisms.

\section{Conflicts of interest}

The authors declare no conflict of interest.

\section{ACKNOWLEDGMENTS}

The authors acknowledge Fapesp (\#processes 2010/13384-3 and \#2011/08376-4), Instituto Nacional de Ciência e Tecnologia em Células-tronco (INCTC), Coordenação de Aperfeiçoamento Pessoal de Nível Superior (CAPES) and Centro de Terapia Celular (CEPID-CTC FAPESP \#2013/08135-2) for financial support. 


\section{REFERENCES}

Anderson S, Bankier AT, Barrell BG, de Bruijn MH, et al. (1981). Sequence and organization of the human mitochondrial genome. Nature 290: 457-465.

Armand R, Channon JY, Kintner J, White KA, et al. (2004). The effects of ethidium bromide induced loss of mitochondrial DNA on mitochondrial phenotype and ultrastructure in a human leukemia T-cell line (MOLT-4 cells). Toxicol. Appl. Pharmacol. 196: 68-79.

Armstrong L, Tilgner K, Saretzki G, Atkinson SP, et al. (2010). Human induced pluripotent stem cell lines show stress defense mechanisms and mitochondrial regulation similar to those of human embryonic stem cells. Stem Cells 28: 661-673.

Champelovier P, Chauchet X, Hazane-Puch F, Vergnaud S, et al. (2013). Cellular and molecular mechanisms activating the cell death processes by chalcones: Critical structural effects. Toxicol. In vitro 27: 2305-2315.

Facucho-Oliveira JM and St John JC (2009). The relationship between pluripotency and mitochondrial DNA proliferation during early embryo development and embryonic stem cell differentiation. Stem Cell Rev. 5: 140-158.

Facucho-Oliveira JM, Alderson J, Spikings EC, Egginton S, et al. (2007). Mitochondrial DNA replication during differentiation of murine embryonic stem cells. J. Cell Sci. 15: 4025-4034.

Jeng JY, Yeh TS, Lee JW, Lin SH, et al. (2008). Maintenance of mitochondrial DNA copy number and expression are essential for preservation of mitochondrial function and cell growth. J. Cell Biochem. 103: 347-357.

Kelly RD, Sumer H, Mckenzie M, Facucho-Oliveira J, et al. (2013). The effects of nuclear reprogramming on mitochondrial DNA replication. Stem Cell Rev. 9: 1-15.

King MP and Attardi G (1996). Isolation of human cell lines lacking mitochondrial DNA. Methods Enzymol. 264: 304-313.

Livak KJ and Schmittgen TD (2001). Analysis of relative gene expression data using real- time quantitative PCR and the 2(-Delta Delta C(T)) Method. Methods 25: 402-408.

Magda D, Lecane P, Prescott J, Thiemann P, et al. (2008). mtDNA depletion confers specific gene expression profiles in human cells grown in culture and in xenograft. BMC Genomics 9: 521.

Marusich MF, Robinson BH, Taanman JW, Kim SJ, et al. (1997). Expression of mtDNA and nDNA encoded respiratory chain proteins in chemically and genetically-derived Rho0 human fibroblasts: a comparison of subunit proteins in normal fibroblasts treated with ethidium bromide and fibroblasts from a patient with mtDNA depletion syndrome. Biochim. Biophys. Acta. 1362: 145-159.

Miller SA, Dykes DD and Polesky HF (1988). A simple salting out procedure for extracting DNA from human nucleated cells. Nucleic Acids Res. 16:1215.

Mineri R, Pavelka N, Fernandez-Vizarra E, Ricciardi-Castagnoli P, et al. (2009). How do human cells react to the absence of mitochondrial DNA? PLOS ONE 4: e5713.

Nagata S (1997). Apoptosis by death factor. Cell 88: 355-365.

Nass MM (1970). Abnormal DNA patterns in animal mitochondria: ethidium bromide-induced breakdown of closed circular DNA and conditions leading to oligomer accumulation. Proc. Natl. Acad. Sci. USA. 67: 1926-1933.

Nicklas JA, Brooks EM, Hunter TC, Single R, et al. (2004). Development of a quantitative PCR (Taqman) assay for relative mitochondrial DNA copy number and the common mitochondrial DNA deletion in the rat. Environ. Mol. Mutagen. 44: 313-320.

Ramalho-Santos J, Varum S, Amaral S, Mota PC, et al. (2009). Mitochondrial functionality in reproduction: from gonads and gametes to embryos and embryonic stem cells. Hum. Reprod. Update 15: 553-572.

Reynier P, May-Panloup P, Chrétien MF, Morgan CJ, et al. (2001). Mitochondrial DNA content affects the fertilizability of human oocytes. Mol. Hum. Reprod. 7: 425-429.

Sampaio RV, Chiaratti MR, Santos DC, Bressan FF, et al. (2015). Generation of bovine (Bos indicus) and buffalo (Bubalus bubalis) adipose tissue derived stem cells: isolation, characterization, and multipotentiality. Genet. Mol. Res. 14: 53-62.

Sathananthan H, Pera M and Trounson A (2002). The fine structure of human embryonic stem cells. Reprod. BioMed. Online. 4: 56-61.

Scarpulla RC (2008). Transcriptional paradigms in mammalian mitochondrial biogenesis and function. Physiol. Rev. 88: 611-638.

Schauen M, Spitkovsky D, Schubert J, Fischer JH, et al. (2006). Respiratory chain deficiency slows down cell-cycle progression via reduced ROS generation and is associated with a reduction of p21CIP1/WAF1. J. Cell Physiol. 209:103-112.

Seidel-Rogol BL and Shadel GS (2002). Modulation of mitochondrial transcription in response to mtDNA depletion and repletion in HeLa cells. Nucleic Acids Res. 30: 1929-1934.

Shadel GS and Clayton DA (1997). Mitochondrial DNA maintenance in vertebrates. Annu. Rev. Biochem. 66: 409-435.

Shoubridge EA and Wai T (2007). Mitochondrial DNA and the mammalian oocyte. Curr. Top. Dev. Biol. 77: 87-111.

Sommer CA, Stadtfeld M, Murphy GJ, Hochedlinger K, et al. (2009). Induced pluripotent stem cell generation using a single lentiviral stem cell cassette. Stem Cells 27: 543-549. 
Son MJ, Jeong BR, Kwon Y and Cho YS (2013). Interference with the mitochondrial bioenergetics fuels reprogramming to pluripotency via facilitation of the glycolytic transition. Int. J. Biochem. Cell Biol. 45: 2512-2518.

St John JC, Ramalho-Santos J, Gray HL, Petrosko P, et al. (2005). The expression of mitochondrial DNA transcription factors during early cardiomyocyte in vitro differentiation from human embryonic stem cells. Cloning Stem Cells 7: 141-153.

St John JC, Facucho-Oliveira J, Jiang Y, Kelly R, et al. (2010). Mitochondrial DNA transmission, replication and inheritance: a journey from the gamete through the embryo and into offspring and embryonic stem cells. Hum. Reprod. Update 16: 488-509.

St John J (2014). The control of mtDNA replication during differentiation and development. Biochim. Biophys. Acta 1840: 1345-54.

Thundathil J, Filion F and Smith LC (2005). Molecular control of mitochondrial function in preimplantation mouse embryos. Mol. Reprod. Dev. 71: 405-413. 